\title{
Singleness or Doubleness of the Chromosomes in the Successive Stages of Mitosis
}

Received November 11,1936 *

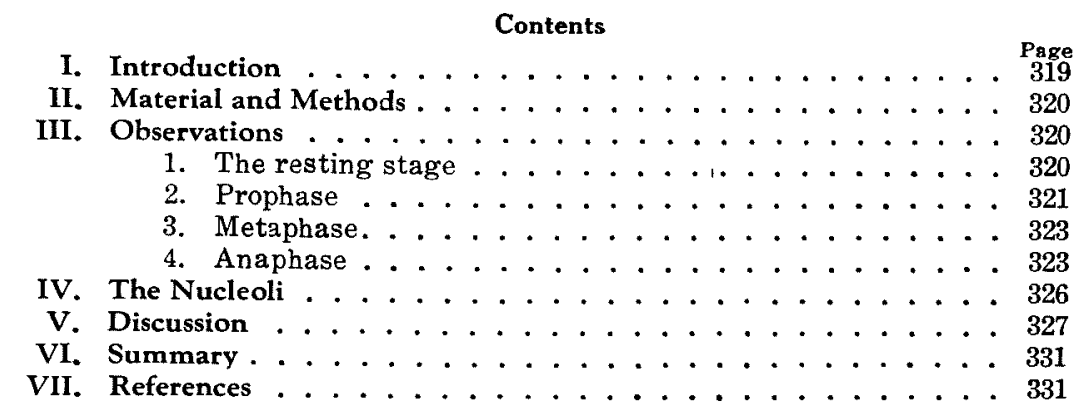

\section{Introduction}

A careful study of mitosis, illustrated with excellent drawings and photomicrographs has been published by Bělar (1929). Since then a good deal of work has been undertaken by various authors with a view to elucidating the more intricate problems to be met with during that process. Such problems as would treat the structure of the chromosomes internally and externally. Various plants were chosen for this study, and obviously those with large chromosomes were preferred, such as Vicia, Tradescantia, Lilium, Rhoeo, Secale, Zebrina, and others (cf. Shinke 1930). This does not mean that prior to Bělař's publication there was no attempt to solve these problems. Actually several papers were published, such as Sands (1923), Belling (1925), Kaufmann (1926), Kuwada and Sugimoto (1926), Kuwada (1927), Maeda (1928), and even a good deal of work was published before 1923. The poor technical methods prevailing then however, did not permit of a thorough investigation of the fine structure of chromosomes. Recent contributions describing these structures with great accuracy are mainly due to improvements in technique and microscopic apparatus.

The writer, in a course of cytological investigation of members of the Cucurbitaceae growing in Egypt, came across some very well

* The circumstance that the corrected proof was not received earlier caused this delay in publication. Editor. 
fixed mitotic stages in the root tips of Cucumis sativus, such stages as would add further evidence to the behaviour of chromosomes during the process of somatic division. It might be mentioned however, that such a study was not in view at the commencement of the work, and hence there was no direct aim to use particular technical methods such as would reveal the internal structure of chromosomes. The point which will be stressed in this article will be the singleness or doubleness of the chromosome threads at the different stages of mitosis, because in this respect opinions vary. As for the internal structure of chromosomes, a good deal of work has been done, particularly by the Japanese and Russian schools of cytologists, and although there is a little difference in opinion, it seems probable that a general agreement may be reachd. It is the general belief amongst all of them that chromosomes are spiral in structure, the details of which however, are still subject for debate: Babcock and Hollingshead (1929), Sax (1930), Taylor (1931), Kuwada and Nakamura (1933, 1934), Iwata (1935), Kato and Iwata (1935), and others. Reference should also be made here to Darlington's treatise of chromosome structure in his book (1932).

\section{Material and Methods}

Material for this study was kindly supplied by my colleague M. Hassib from his breeding plants. Root tips were fixed in various fixatives, of which 2B of La Cour (1931), gave the best results, and all the figures in the text were taken from material fixed in it. Sections were cut at from 8-12 $\mu$ and stained according to Newton's gentian violet method. Drawings were made at bench level, with the aid of a Leitz camera lucida, a $2 \mathrm{~mm}$. apochromatic oil immersion objective, and a $25 \times$ compensating eye-piece. This gives a magnification of 4000 . The drawings were then reduced to the given magnifications.

\section{The resting stage}

\section{Observations}

The nucleus is globular and almost always occupies the middle of the cell. It consists of a network of chromatin threads scattered all over the space occupied by the nucleoplasm, and surrounded by a definite and sharp membrane (Text fig. 1). All nuclei at this stage invariably enclose two spherical nucleoli which are always more deeply stained than the rest of the nuclear contents. (See Pl. 3, photomicrograph 1). A discussion of the behaviour of the nucleoli will be given separately later in the text. 


\section{Prophase}

The prophase is indicated by the appearance of coiled contorted threads which fill up the whole body of the nucleus (Text fig. 2). It is possible in certain nuclei to observe with great accuracy that the threads are double in structure. These threads will resolve themselves into the chromosomes in later stages, and the double structure represents the two chromatids of each chromosome. The two nucleoli have now begun to fuse forming, as is apparent in the figure, a dumb-bell shaped structure constricted in the middle, the place of fusion (see also Pl. 3, photomicrograph 1). At a later stage in prophase, the individuality of the chromosomes becomes very clear (Text fig. 3). They are now definitely seen to be double i.e. each is longitudinally split into two identical halves. The old view of the occurrence of a continuous spireme is contradicted in this material. Actually it is a view which, with a few exceptions in some lower organisms, does not hold any more, and is unjustified on cytological as well as on genetical grounds (cf. Darlington 1932). Observation at this stage shows that the ends of the chromosomes stick to the two nucleoli, which have now completely fused into one large body occupying about one tenth of the total volume of the nucleus. At a later stage still, individual chromosomes can be identified, and their entire length traced from one end to the other. It was impossible however, to recognise the full complement to this extent, because the chromosomes lie over each other in such a manner that tracing them was impracticable. Text fig. 4 shows three such chromosomes taken from one nucleus and drawn out side by side. They are clearly seen to be double throughout their entire length, except at one point. This point is the attachment constriction which holds the two chromatids of each chromosome tightly, while elsewhere they may lie loosely parallel. The two chromatids will eventually come to lie near one another as the division proceeds, and by the time the stage of full metaphase is attained, they will appear as one thread throughout their length. Actually the double structure persists but is not apparent, and is next seen at the beginning of anaphase when separation between the two chromatids first begins at the point of constriction, as has clearly been demonstrated in Crocus: Mather (1932).

The threads shorten and thicken, and later in prophase, although the individual chromosomes can be identified with more ease, the full complement was still unintelligible. Text fig. 5 illustrates six chromosomes taken from one nucleus. The two chromatids of each chromosome are now more attracted towards one another, and they have come together in more than one point. The points of the at- 


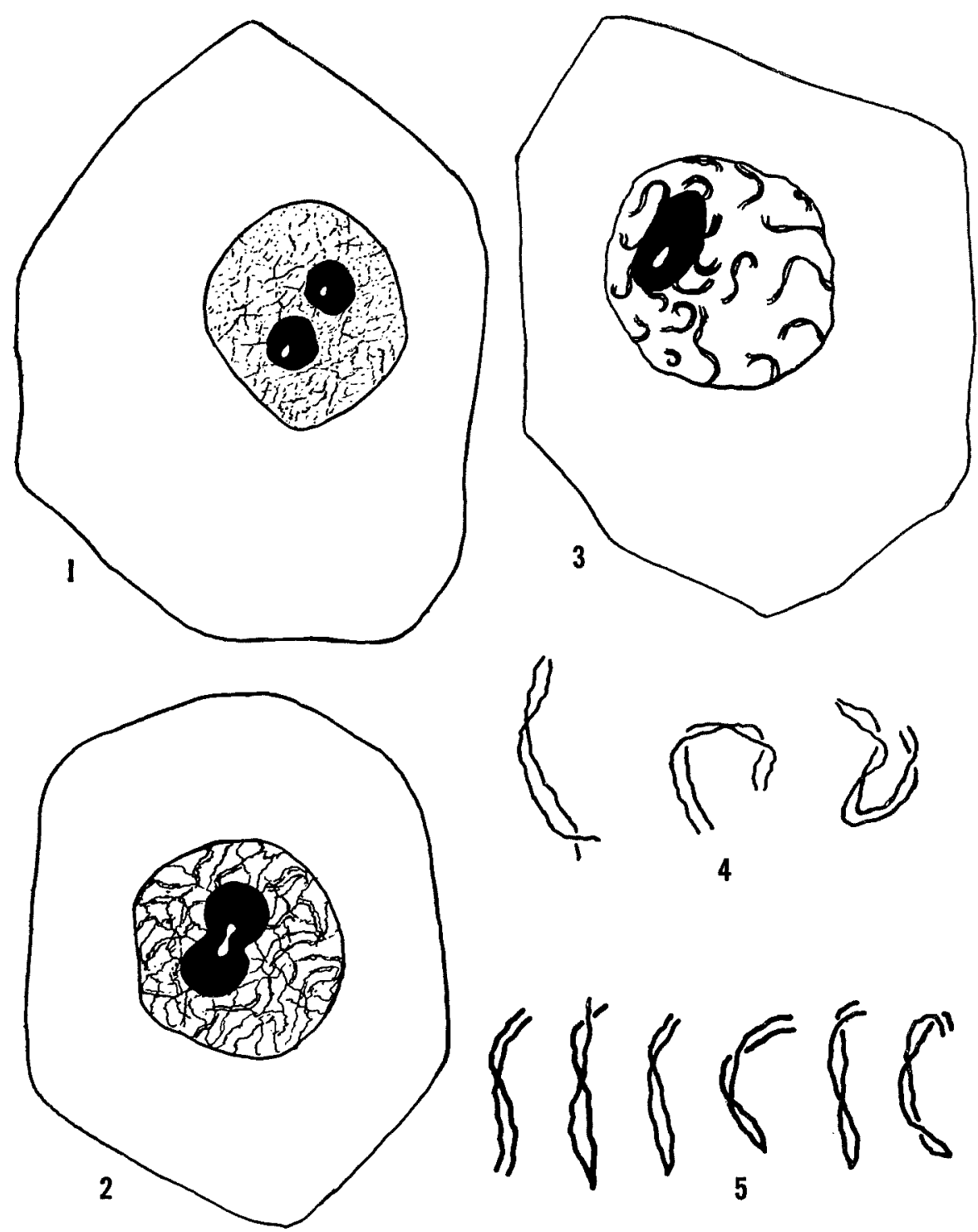

Text figs. 1-5. 1. A cell in the resting stage, showing the network of chromatin threads, and the two nucleoli, $\times 2000$. 2. A cell in the early prophase stage. The chromatin threads can be seen to be double, and the two nucleoli bave begun to fuse forming a dumb-bell shaped body, $\times 2000$. 3. A cell in late prophase. The chromosomes are definitely double in structure, and the two nucleoli have now completely fused into one large nucleolus, $\times 2000$. 4. Three individual chromosomes traced from one nucleu in prophase and drawn side by side. Each is double throughout its entire length except at one point-the point of the attachment constriction, which is single, $\times 2000$. 5. Six chromosomes taken from one nucleus at late prophase. They are thicker and show more clearly the same structure as in Fig. 4, $\times 2000$. 
tachment constrictions are still single. Indeed they will remain as such until the force of anaphase separation begins action.

By this stage of late prophase, the one large nucleolus has almost completely disappeared.

The conclusion which concerns us from this study of prophase is that throughout this stage, the chromosome threads are longitudinally split. They are double in structure all through their lengths except at the points of the attachment constrictions which are single. Pl. 3 , photomicrographs 2 and 3 clearly show the doubleness of the chromosome threads at this stage.

\section{Metaphase}

Text fig. 6 shows a somatic metaphase plate. This stage actually represents an early metaphase, because complete union of the two members of each chromosome has not yet been attained. A stage of full metaphase was not observed in this material, which might be due to a short period of existence. Duration of mitosis has a wide range of variation, and observation of successive stages by Bělar on Tradescantia $(1926,1929)$, clearly supports this phenomenon. The present is a case in which metaphase proper exists for only a very short period. The somatic complement consists of 14 chromosomes $(2 \mathrm{n}=14)$. The same number in this species has been reported by Kozhukhow (1930), Passmore (1930), and Whitaker (1930). The position of the attachment constriction seems to be the same in all chromosomes, viz. sub-terminal, except for one pair which might be considered as having a sub-median constriction. The chromosomes can be arranged in twos indicating a case of normal diploidy, and unlike the chromosome complements observed in such plants as Oenothera: Darlington (1931), Aconitum: Afify (1933), and other structural hybrids. The chromosomes are clearly double in structure except at the attachment constrictions. The distal arms of the chromosomes are comparatively long and hence do not lie in the plain of vision. Focussing up to trace these ends shows the double structure very clearly (Text fig. 7). Thus as in prophase, the same conclusion can be drawn as to the doubleness of the chromosomes. (See Pl. 3, photomicrographs 4 and 5).

\section{Anaphase}

At anaphase the two chromatids of each chromosome separate from each other (Text fig. 8). The two poles of an anaphase stage are also seen in $\mathrm{Pl}$. 3, photomicrograph 6 . The threads here are single, which is in accord with expectation, as each of the anaphase threads represents a chromatid of one of the original chromosomes. The 
singleness of the threads is further demonstrated in Text figs. 9 and 10 , the former of which is a top inclined view of the cones of one of the anaphase poles, and the latter a top view of the ends of the chromosomes after focussing up to trace them (see Pl. 3, photomicro-
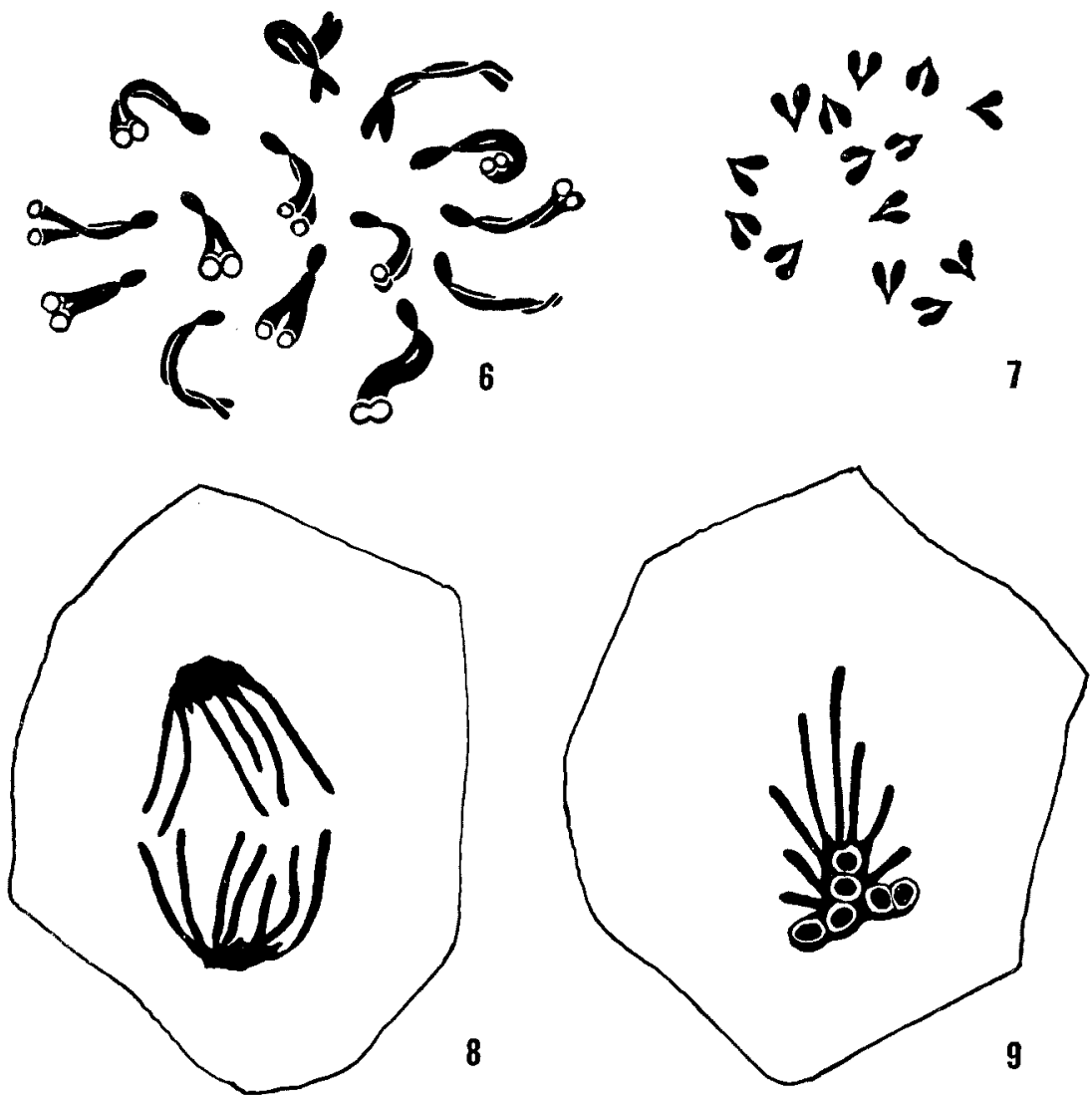

Text figs. 6-9. 6. A full somatic early metaphase plate, with 14 chromosomes showing in each singleness at the attachment constriction and doubleness elsewhere, $\times 2000$. 7 . The top ends of the 14 metaphase chromosomes drawn in one level after focussing up to trace them. Each end is double in structure representing the two chromatids of each chromosome, $\times 2000$. 8. An anaphase stage with chromosomes separating to opposite poles of the spindle. Each is single as it corresponds with one half of a metaphase chromosome, $\times 2000$. 9. A top inclined view of a cone of one of the anaphase poles seen from the inside of the cone. There are 14 ends, all of which are single in structure, $\times 2000$.

graph 7). A comparison of this stage with that shown in Text fig. 7, representing the same view at metaphase is conclusive. One is double and the other single. In both cases the full number of chromosomes can be seen. In the case of metaphase there are 14 double ends ( 28 chromatids), and in anaphase there are 14 single ends (14 chroma- 
tids), which will eventually resolve themselves into chromosomes in readiness for the following division. So it can be concluded that the anaphase chromosomes are single. This singleness persists until later when, at an early telophase (Text fig. 11), the ends can still be seen in the single condition protruding from the tassement polaire. After this stage the nucleus will enter into a resting stage for the next division.
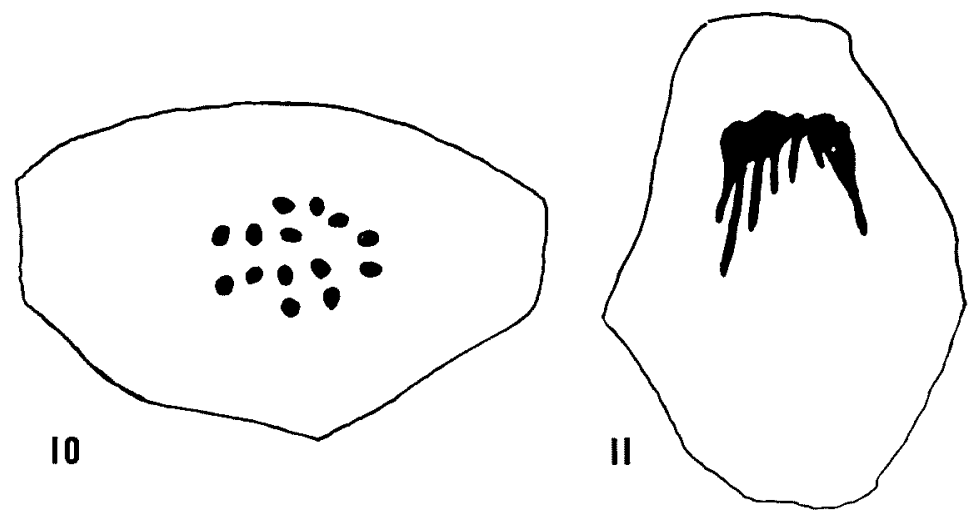

Text figs. 10-11. 10. The top ends of the 14 anaphase chromosomes traced up in focussing. They are single in contrast with those of the metaphase ends shown in Fig. 7, $\times 2000$. 11. A tassement polaire at telophase showing some protruding ends of chromosomes. They are seen to remain single up to this stage, $\times 2000$.

Diagram 1 illustrates the changes undergone by a chromosome from prophase until telophase with respect to the state of singleness or doubleness in the various stages. It can be safely stated that soon after the resting stage, the chromosome threads are double. They

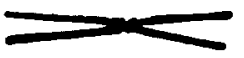

a

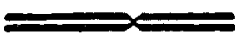

b

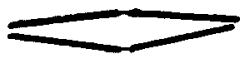

c

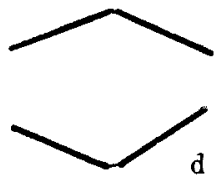

Diagram 1. A diagramatic representation illustrating the changes undergone by one chromosome throughout the various mitotic stages. $a=$ prophase $b=$ metaphase $c=$ early anaphase $d=$ late anaphase.

remain so during the stages of prophase and metaphase. The anaphase chromosomes are single, and they are seen as such until as late in telophase as observation permits. So the last we have seen of the chromosomes they were single, and the first we see of them they are double. The significance of this will be discussed later. 


\section{The Nucleoli}

The nucleolus has been a subject of controversy among cytologists. There is little agreement as regards its composition, function, and behaviour during cell division. It has been assumed to be composed of chromatin, the evidence being the similarity of staining properties with the chromosomes. It was thus taken to constitute a reserve supply of chromatin which will disappear on the initiation of mitosis, as the contents become incorporated in the developing chromosomes. Other cytologists have described nucleoli which are composed of plastin and not chromatin, and these of course do not contribute to the chromosomes, but disintegrate and disappear (cf. Wilson 1925). The confusion in this point is actually due to differences in the technical methods applied.

The number of nucleoli varies amongst organisms. In Pinus, for instance, Zirkle (1931), there are normally from 5 to 7 nucleoli, a plurality which is characteristic of a number of Gymnosperms. In some varieties of Oryza sativa, Selim (1930), there are primary and secondary nucleoli, and the author is inclined to support the view that the secondary nucleoli contribute material to the chromosomes, while the primary contribute to the spindle. Most of the Angiosperms however, usually show only one or two nucleoli at the resting stage. Discussions on the function of nucleoli are merely speculative and mainly based on deductive principles. Their behaviour, on the other hand, can be described and discussed with more accuracy, because, in this case, the argument is based on material evidence i.e. on actual observation. For instance, although it is the general belief that nucleoli break up and gradualy disappear as the nucleus is activated, yet in some cases the nucleolar material may persist until metaphase. Such behaviour has been observed in a number of plants. Such as Helianthus, Dembowski and Ziegenspeck (1928), Zea mays, Zirkle (1928), and others. (cf. Dembowski 1930, Schader 1928, Yamaha and Sinotô 1925, and Van Camp 1924). Even as late as telophase, nucleolar material was still present as small bodies, De Mol (1926). In Vicia amphicarpa, Abele (1925), the nucleolus divides into two, but the further behaviour of these resulting nucleoli was not described. Frew and Bowen (1928), describe a different behaviour which they observed in some members of the Cucurbitaceae. The resting nucleus has one large spherical nucleolus which wholly or partly dissolves at prophase. The remaining parts, if any, orientate themselves on the equatorial plate of the spindle, are constricted in the middle, and divide into two which migrate to the opposite poles, thus behaving as ordinary chromosomes. 
In the present study, a unique case in the Cucurbitaceae is described. The resting nucleus has two nucleoli, which begin to fuse into one large nucleolus as division proceeds. On this one large body the chromosomes were seen to stick, and look as though they come out of it. As the nucleus advances in mitosis, the nucleolus gradually disappears, and by metaphase it exists no more. The writer is inclined to interpret this behaviour as evidence in support of the theory considering the nucleoli as chromatin reservoirs. The two nucleoli of the resting nucleus first fuse into one large reservoir which disappears after having emptied its contents in the developing chromosomes.

This seems to be the only plausible explanation of the fusion and then disappearance of the two nucleoli of the resting stage. Otherwise why did they not disappear without fusion?.

\section{Discussion}

Mitosis is the process by which the nucleus divides. Certain features of this process, particularly those of genetic significance, have been proved to be universally applicable, and these consist in the fact that the identical halves of each chromosome separate from one another at anaphase, and the groups of half chromosomes going to one pole or the other will constitute a daughter nucleus which, other things being equal, will be the mirror image of the original nucleus. Here one can make a correction of what was previously thought to be the sequence of events at anaphase, vis. that at this stage, the chromosomes split into identical halves. This is an error of observation, because at this stage the chromosomes are already split. Indeed they have split at a much earlier stage, as will be seen later. So what actually happens at anaphase is that the two component chromatids of each chromosome simply go apart from one another, after having been firmly held together up to this stage by a force of attraction between them, and by virtue of the state of singleness of the attachment constriction.

The singleness of this point of attachment has a great significance in the process of meiosis, especially in interpreting genetical results. Evidence is adduced that identical chromatids remain together at the attachment constriction as it behaves as a single unit until anaphase. Although there is no cytological evidence to prove the validity of this assumption, yet evidence from the genetics of Drosophila, Bridges (1925), Bridges and Anderson (1925), Morgan (1925), Redfield (1930), and others, indicate that identical chromatids are actually held together at the point of attachment during the first 
meiotic division, and that they do not separate from each other until the anaphase of the second division (which is a simple mitotic division). This rule has its importance in polyploids with regards to the interpretation of segregation of characters (cf. Sansome and Philp 1932). Those characters which are borne at or near the attachment constriction, and which will thus be controlled by its unity, will always remain together and pass to the same pole at the first anaphase, and will only segregate from one another at the second anaphase. But those, on the other hand, which are situated away from the sphere of influence of the attachment constriction can behave otherwise. This expectation, which is based on general cytological and genetical observations, has been verified by the results of a study of inheritance in tetraploid Rubus rusticanus: Crane and Darlington (1932), and Solanum lycopersicum: Sansome (1933), and particularly agrees with the chiasmatype hypothesis of crossing over: Darlington (1930). The present investigation confirms the foundation of these theories i.e. that the attachment constriction behaves as a single unit. Although here the study was on mitosis alone, yet the analogy with the second meiotic division, which is a mitotic one, is clear. Here cytologically, and there, cytologically as well as genetically, it is confirmed that not before the onset of the mitotic anaphase does the attachment constriction split or divide, and this puts an end to its control on the two component chromatids of each chromosome. They can then, and only then, segregate from one another. This parallelism between the two mitotic phases, might have some weight in supporting Darlington's hypothesis (1932), that meiosis is a modification of mitosis. It is a single step mutation from the mitotic division.

Chromosomes are best defined, according to Darlington, as bodies into which the nucleus resolves itself at the beginning of mitosis, and from which it is derived at the end of mitosis. Between the beginning and the end of mitosis, the chromosomes undergo a series of changes, structurally as well as morphologically. The stage which is best suited for a thorough study of chromosome morphology is metaphase, because by this stage, the chromosomes would have attained their maximum thickness, and have become a compact mass of chromatin which is least liable to alterations by the fixatives used. Every chromosome is then seen to possess an attachment constriction which, if not terminal, divides the body of the chromosome into two segments, a distal and a proximal one. There is no further doubt as to the condition of the attachment constriction. It is a single unit from as early in prophase as the identity of the chromosomes can be revealed until anaphase. The condition of the other parts of the chromosomes, as regards singleness or doubleness in the various stages, has been 
discussed by several authors, and there still remains some discrepancy as to the actual state of affairs.

There are two points of view as to the time of division of the chromosomes at mitosis. Robertson (1931), has concluded that the chromosomes have already split at anaphase for the following division. Hedayetullah (1931), has advanced a similar view from his observation on Narcissus. He considers his observations to demonstrate the fact that the chromosomes split at metaphase of one mitosis for the next division. The same conclusion has been put forward by Koshy (1933) on Allium. The opposite view considers the chromosomes to be single at anaphase and telophase, while they are double at prophase and metaphase. The missing link is the resting stage, and the view is held that splitting takes place at this stage: Darlington (1931). The former point of view can be discarded on several grounds which Darlington has analysed in detail (1932). The main objection as to the doubleness of the chromosomes at anaphase lies in the fact that such a condition is incompatible with two series of observations. First, the assumed split of the anaphase threads should cut across the spiral structure found in anaphase chromosomes: Kuwada and Sugimoto (1926), and second, if the chromosomes have already split at the preceding anaphase, there should be two independent spirals side by side at the next prophase.

Evidence in support of the latter view has accumulated in recent years, and is derived from several aspects of chromosome behaviour :-

1. From meiosis: The chromosome threads are always single at the earliest prophase of meiosis: Newton and Darlington (1929), and Darlington (1929b). As this prophase follows a normal mitotic telophase, resulting from a previous mitotic anaphase, there could be no other alternative than that the chromosomes at these two latter stages were single. This condition of singleness at the early prophase of meiosis, has formed the foundation of Darlington's theory of the precocity of meiosis (1931), which regards meiosis as a modification of mitosis, the only essential difference being that the chromosomes are split at the very early prophase of mitosis, while they do not do so until the pachytene stage of the prophase of meiosis, by which time the chromosomes would have associated in pairs to satisfy their pairing affinities. This theory has a far reaching significance in as much as it affords a simple explanation to such problems as failure of chromosome pairing, configurations observed in polyploids, numerical and structural hybrids, and also to the occurrence of such phenomena as meiosis, sex, and fertilization. 
2. From $\mathrm{X}$-radiation of somatic chromosomes: Ever since Muller's discovery (1930) of the effect of X-rays in producing variations in Drosophila, and similarly by others in Zea mays, a good deal of work has been devoted to X-raying plants and animals with a view to clarifying some of the cytological and genetical problems existing at the time. Such X-rayed material has yielded a number of abnormalities in chromosome behaviour and structure, from which evidence can be adduced in support of the view under discussion in this article. Stone (1933), has illustrated certain types of abnormalities in the meiotic divisions of some plants. He showed that Crocus exhibits three phases after irradiation: first, those nuclei which were actually dividing during irradiation, completed their course normally; second, those which were in the resting stage showed no signs of mitosis during this period; and third, division begins again and the chromosomes show the abnormalities. An extension of this work by Mather and Stone (1933), gave a conclusive evidence with regards to the time of division of chromosomes in mitosis. As there were no apparent changes in the nuclei which were dividing during irradiation, it was concluded that the production of chromosome abnormalities must have taken place during the long enforced resting stage. The types of abnormalities observed after this period cannot be explained by any other way than by assuming that the chromosomes split during the resting stage. The abnormality was always equally represented in the two chromatids of the chromosome, and not in one alone. This means that the abnormality occurs first, thus affecting the chromosome as a single body, and then splitting takes place producing two chromatids exhibiting the same change. The conclusion is therefore that the chromosomes are single as they enter the resting stage, and become double during this stage.

3. From the present investigation: The present study, based on observation, is also conclusive in support of the view at issue. The chromosomes were seen to be double all through their length, except at the attachment constriction, from the early prophase. They remained so until metaphase. The anaphase as well as the telophase chromosomes were seen to be single, and then they go into the resting stage. So obviously the essential change that must have taken place during the resting stage, is that the chromosomes split longitudinally into two identical halves. The last we see of the chromosomes they are single (anaphase-telophase), and the first we see of them, they are double (prophase-metaphase). We do not see them at the resting stage, and that is where the change from singleness to doubleness must have taken place. 


\section{Summary}

1. A study of chromosome behaviour at mitosis in the Egyptian variety of Cucumis sativus is described.

2. The number of chromosomes is $2 \mathrm{n}=14$.

3. The chromosomes were observed to be double in structure at prophase and metaphase.

4. The chromosomes were single in structure at anaphase and telophase.

5. Evidence from meiosis, from the effect of X-radiation on somatic chromosomes in other plants, and from the present investigation is conclusive in supporting the view that the effective splitting of the chromosomes takes place during the resting stage.

6. The behaviour of the nucleoli in relation to other plants is discussed.

\section{References}

1. Abele, K. (1925). Sur les nucleoles des cellules radicales de Vicia amphicarpa Dorthes. Soc. Biol. de Lettonie Séanc. Nov. 1924 et Jan, 1925: 11-12.

2. Afify, A. (1933). Chromosome form and behaviour in diploid and triploid Aconitum. Jour. Gen. 27: 293-318.

3. Babcock, E. B. and Hollingshead, L. (1929). Crepis ruteriana and its chromosomes. Science $69: 356$.

4. Bèlař, K. (1926). Zur Cytologie von Aggregata eberthi. Arch. Prot. 53: 312-325.

5. _ (1929). Beiträge zur Kausalanalyse der Mitose III. Arch. f. Entwn. 118: $359-484$.

6. Belling, J. (1925). The structure of chromosomes. Brit. Jour. Exp. Biol. 3.

7. Bridges, C. B. (1925). Eliminations of chromosomes due to a mutant (minute $\mathrm{n}$ ) in Drosophila melanogaster. Proc. Nat. Acad. Sci. 11: 701-706.

8. - and Anderson, E. G. (1925). Crossing over in the X chromosomes of triploid females of Drosophila melanogaster. Genetics 10: 418-441.

9. Crane, M. B. and Darlington, C. D. (1932). Chromatid segregation in tetraploid Rubus. Nature 129: 189.

10. Darlington, C. D. (1929 b). Meiosis in polyploids II. Jour. Gen. 21 : 17-56.

11. - (1930). A cy tological demonstration of genetic crossing over. Proc. Roy. Soc. B. $107: 50-59$.

12. - (1931 b). Cy tological theory in relation to heredity. Nature $127: 709-712$.

13. - $(1931 \mathrm{c})$. Meiosis. Biol. Revs. $6: 22 \mathrm{l}-264$.

14. - $(1931 \mathrm{~d})$. The cytological theory of inheritance in Oenothera. Jour. Gen. 24: $405-474$.

15. - (1932). Recent advances in cytology. Churchill, London.

16. Dembowski, J. (1930). Karyologische Studien an Wurzelmeristemen höhrer Pflanzen. Bot. Archiv. 28: 1-56.

17. — and Ziegenspeck, H. (1928). Über das Verhalten der Nukleolen bei der Kernteilung in der äussersten Meristemzone von Wurzelen von Helianthus. Bot. Archiv. 22: 571-574.

18. Frew, E. and Bowen, R. E. (1929). Nucleolar behaviour in the mitosis of plant cells. Q. Jour. Micr. Soc. 73: 197-214.

19. Hedayatullah, S. (1931). On the structure and division of the somatic chromosomes in Narcissus. Jour. Roy. Micr. Soc. 51 : 347-386.

20. Iwata, J. (1935a). Chromosome structure in Lilium. Mem. Coll. Sci. Kyoto Imp. Univ. B. $10: 275-288$. 
21. Kato, K. and Iwata, J. (1935). Spiral structure of chromosomes in Lilium. Ibid. $10: 263-273$.

22. Kaufmann, B. P. (1926). Chromosome structure in relation to chromosome cycle I. Somatic mitosis in Tradescantia pitosa. Am. Jour. Bot. 13.

23. Koshy, F. K. (1933). Structure and division of somatic chromosomes in Allium. Nature 131: 362.

24. Kozhukhow, S. A. (1930). Karyological investigation of the genus Cucumis. Bull. Appl. Bot. Pl. Breed. 23: 357-366.

25. Kuwada, Y. (1927). On the spiral structure of chromosomes. Bot. Mag. (Tokyo) 41: 100-109.

26. — and Nakamura, T. (1933). Behaviour of chromonemata in mitosis. I. Observations of pollen mother cells in Tradescantia reflexa. Mem. Coll. Sci. Kyoto Imp. Univ. B. $9: 129-139$.

27. - - and Nakamura, T. (1934). Behaviour of chromonemata in mitosis. III. Observations of living staminate hair cells in Tradescantia reflexa. Ibid. 9: $343-366$.

28. - and Sugimoto, T. (1926). On the structure of the chromosomes in Tradescantia virginica. Bot. Mag. (Tokyo) 40:19-20.

29. La Cour, L. (1931). Improvements in everyday technique in plant cytology. Jour. Roy. Micr. Soc. 51 : 119-126.

30. Maeda, T. (1928). The spiral structure of chromosomes in the sweet-pea (Lathyrus odoratus) Bot. May. (Tokyo) .42:191-195.

31. Mather, K. (1932). Chromosome variation in Crocus. I. Jour. Gen. 26 : 129-142.

32. - and Stone, L. H. A. (1933). The effect of X-radiation upon somatic chromosomes. Jour. Gen. 28: 1-24.

33. Mol, W. E. De. (1926). The nucleolar globules regarded as bearers of stimulating or finishing material of the genes. Genetica. 8: 637-542.

34. Morgan, L. V. (1925). Polyploidy in Drosophila melanogaster with two attached $\mathrm{X}$-chromosomes. Genetics 10: 148-178.

35. Muller, H. J. (1930). Types of visible variations induced by X-rays in Drosophila. Jour. Gen. $22: 299-334$.

36. Newton, W. C. F. and Darlington, C. D. (1929). Meiosis in polyploids I. Jour. Gen. $21:$ 1-15.

37. Passmore, S. F. (1930). Microsporogenesis in the Cucurbitaceae. Bot. Gaz. 90: $213-223$.

38. Redfield, H. (1930). Crossing over in the third chromosomes of triploids of Drosophila melanogaster. Genetics 15: 205-252.

39. Robertson, W. R. B. (1931). Chromosome studies II. Synapsis in the Tettigidae with special reference to the prosynapsis split. Jour. Morphology. 51: 119-139.

40. Sands, H. C. (1923). The structure of the chromosomes in Tradescantia virginica L. Am. Jour. Bot. 10: 343-360.

41. Sansome, F. W. (1933), Chromatid segregation in Solanum lycopersicum. Jour. Gen. $27:$ 105-132.

42. - - and Philp, J. (1932). Recent advances in plant genetics. Churchill, London.

43. Sax, K. (1930). Chromosome structure and the mechanism of crossing over. Jour. Arnold Arbor. 11 : 193-220.

44. Schaede, R. (1928). Vergleichende Untersuchungen über Cytoplasma, Kern, und Kernteilung im lebenden und im fixierten Zustand. Protoplasma 3 : 145190 .

45. Selim, A. G. (1930). A eytological study of Oryza sativa L. Cytologia 2: 1-26.

46. Shinke, N. (1930). On the spiral structure of chromosomes in some higher plants. Mem. Coll. Sci. Kyoto Imp. Univ. B. 5 : 239-245.

47. Stone, L. H. A. (1933). The effect of $\mathrm{X}$ - radiation on the meiotic and mitotic divisions of certain plants. Ann. Bot. 47:815-826.

48. Taylor, W. R. (1931). Chromosome studies on Gasteria III. Chromosome structured uring microsporogenesis and the postmeiotic mitosis. Am. Jour. Bot. A. 18.

49. Van Camp, G. M. (1924). Le role du nucleole dans la caryocinèse somatique. La Cellule $43: 7-60$. 


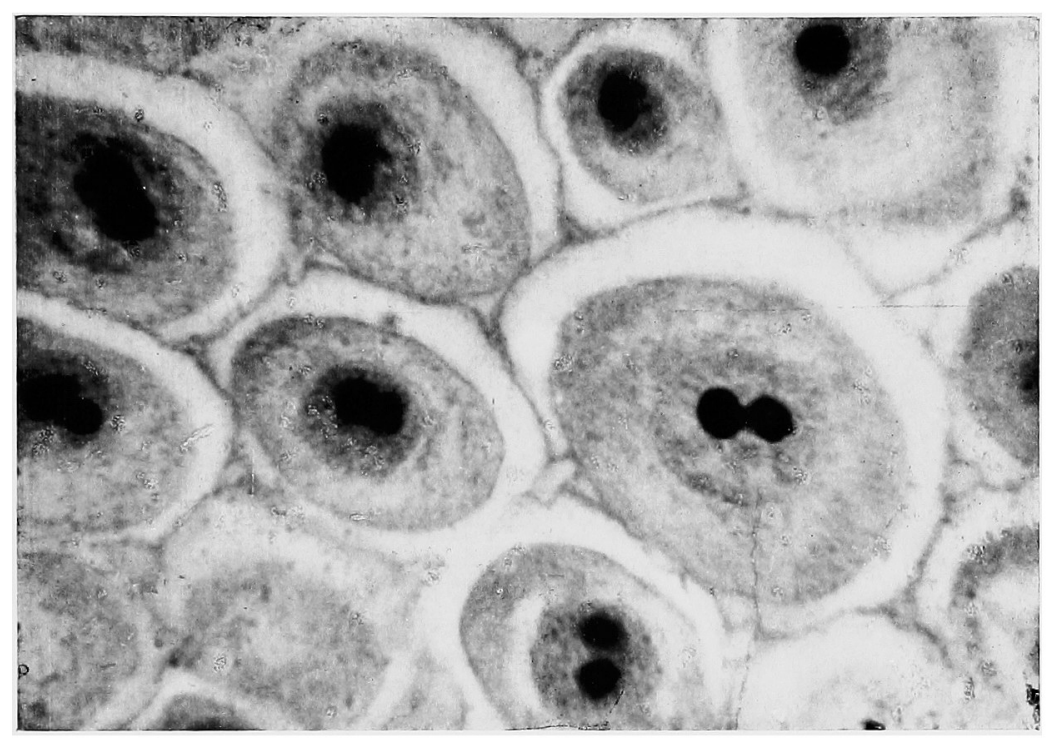

1
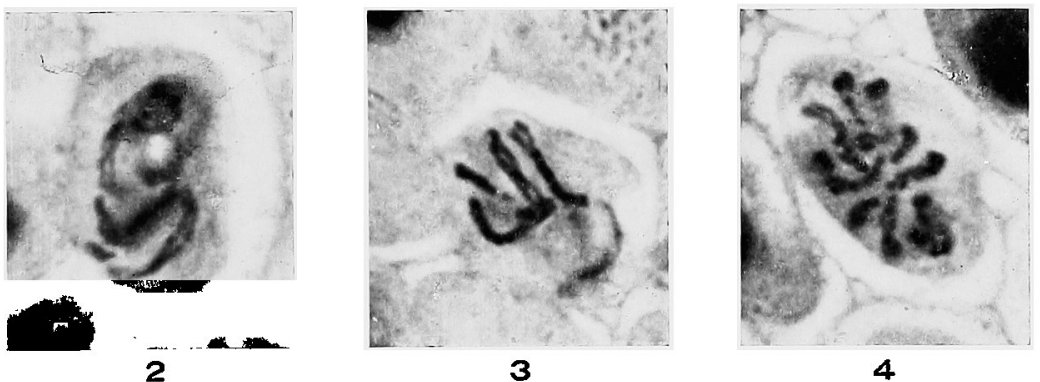

4

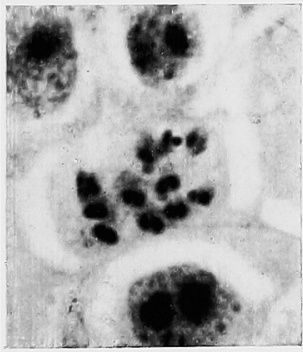

5

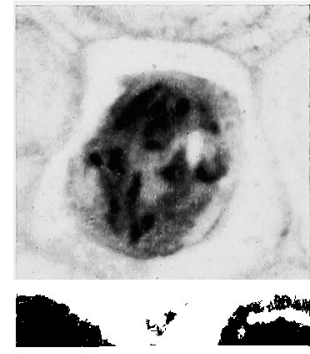

6

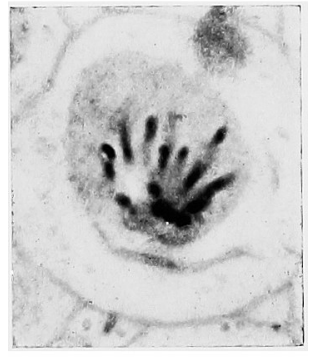

7

A fify: Singleness or Doubleness of the Chromosomes in the Successive Stages of Mitosis 
50. Whitaker, T. W. (1930). Chromosome numbers in the cultivated Cucurbits. Am. Jour. Bot. 17 : 1033-1040.

51. Wilson, E. B. (1925). The cell in development and heredity. New York.

52. Yamaha, G. and Sinotô, Y. (1925). On the behaviour of the nucleolus in the somatic mitosis of higher plants, with microchemical notes. Bot. Mag. (Tokyo) 39 : 205-226.

53. Zirkle, C. (1928). Nucleolus in root tip mitosis in Zea mays. Bot. Gaz. 86 : 402418.

54. _- (1931). Nucleoli of the root tip and cambium of Pinus strobus. Cytologia 2 : 85-105.

\section{Explanation of Plate 3 \\ (Photomicrographs 1-7)}

1. Cells showing various phases of nucleolar behaviour. Some have two nucleoli, some with the two beginning to fuse into a dumb-bell shaped structure, and others with one large nucleolus.

2. A nucleus in early prophase. The chromosome threads are seen to be double in structure.

3. A late prophase with chromosomes shorter and thicker. The double nature of the chromosomes is very clear.

4. A nearly metaphase stage showing the chromosomes still in the double condition. Each consists of two chromatids which are firmly held together at the attachment constriction, the only single point throughout the length of the chromosome.

5. A top view of the metaphase chromosomes after focussing up to trace them. The ends are obviously double representing the two chromatids of each chromosome.

6. An anaphase stage with chromosomes separating to opposite poles. Each is one of the chromatids of a metaphase chromosome and hence single in structure.

7. A top inclined view of one of the anaphase cones clearly showing the singleness of the chromosomes. (Compare with photomicrogr. 5). 